Especial: Humanismo e investigación: una actividad permanente en la Escuela de Estudios Generales

II Parte

Las profesoras y profesores de la Escuela de Estudios Generales investigan

\title{
Aurenthal: maravilla y meta literatura
}

\author{
Juan Pablo Morales Trigueros \\ Universidad de Costa Rica, Costa Rica \\ jppmorales@gmail.com \\ https://orcid.org/0000-0001-9286-1024
}

Recibido:10 de enero de 2019

Aceptado: 31 de enero de 2019

Resumen: La novela Aurenthal, publicada por Luis Ricardo Rodríguez en 1991, destaca como un texto lleno de características que lo acercan a la literatura de corte fantástico. Sin embargo, una observación atenta revela que hay mecanismos narrativos innovadores en sus páginas, tanto desde la lectura de los propios hechos narrados como desde la apreciación de los recursos estilísticos utilizados para narrarlos. A partir de las propuestas teóricas de Todorov y Tolkien, así como de las consideraciones estéticas de Baum, el presente artículo analiza la novela en busca de su lugar dentro de la teoría de lo fantástico y lo maravilloso, así como de las posibilidades interpretativas de sus mecanismos narrativos.

Palabras claves: Literatura fantástica; Literatura Maravillosa; Literatura costarricense; Aurenthal; Meta literatura

\section{Aurenthal: wonder and meta literature}

Abstract: Aurenthal, a novel published by Luis Ricardo Rodríguez in 1991, has many features that could be considered part of the fantastic. However, a close inspection reveals that there are innovative narrative devices in its pages, from the actual story to the stylistic resources used to tale it. From the theoretical proposals

\section{(c) (i) (2) (2)}

La Revista Estudios es editada por la Universidad de Costa Rica y se distribuye bajo una Licencia Creative Commons Atribución-NoComercial-CompartirIgual 3.0 Costa Rica. Para más información envíe un mensaje a 
Especial: Humanismo e investigación: una actividad permanente en la Escuela de Estudios Generales

of Todorov and Tolkien, as well as Baum's stylistic considerations, this work analyze the novel looking for its place in the fantastical and the marvelous theory, and in the interpretative possibilities of its narrative devices.

Keywords: Fantastic Literature; Wonderful Literature; Costa Rican Literature; Aurenthal; Meta literature

Introducción

El término "literatura fantástica" se usa indiscriminadamente para referirse a muchos tipos de textos que, si bien suelen guardar elementos en común, se diferencia notablemente. A nivel teórico existen presupuestos no difundidos en la opinión popular, por lo que no es raro encontrar posiciones diversas e, incluso, contradictorias. Por ejemplo, existen colecciones de "literatura fantástica" enfocadas en textos llenos de dragones y magia, cuando a nivel académico es probable que ese tipo de narrativas se cataloguen de otra manera.

El presente artículo analiza la novela costarricense Aurenthal, publicada por Luis Ricardo Rodríguez en 1991, a la luz de diversas teorías de lo fantástico en busca de comprender sus códigos estéticos y determinar su categoría analítica.

\section{Todorov y su propuesta tripartita}

En su libro Introducción a la literatura fantástica, Tzvetlan Todorov (1974) propuso una clasificación para comprender los textos fantásticos. Así, lo fantástico ocurre cuando en un mundo que es el nuestro, el que conocemos, sin diablos, sílfides ni vampiros se produce un acontecimiento imposible de explicar por las leyes de ese mismo mundo familiar (p. 34).

\section{(c) (i) (9)}

La Revista Estudios es editada por la Universidad de Costa Rica y se distribuye bajo una Licencia Creative Commons Atribución-NoComercial-Compartirlgual 3.0 Costa Rica. Para más información envíe un mensaje a 
Especial: Humanismo e investigación: una actividad permanente en la Escuela de Estudios Generales

No obstante, para Todorov lo fantástico solo lo será en cuanto dicho acontecimiento permanezca sin explicación, creando tensión epistemológica tanto en los personajes como en el lector, quien finalmente tiene en sus manos la decisión de a qué género pertenece el texto:

Si decide que las leyes de la realidad quedan intactas y permiten explicar los fenómenos descritos, decimos que la obra pertenece a otro género: lo extraño. $\mathrm{Si}$, por el contrario, decide que es necesario admitir nuevas leyes de la naturaleza mediante las cuales el fenómeno puede ser explicado, entramos en el género de lo maravilloso (p. 53).

Lo fantástico se propone así como una suerte de límite entre dos géneros, lo extraño y lo maravilloso, un género intermedio que se "desvanece" una vez son explicados o aceptados los acontecimientos aparentemente sobrenaturales.

La noción de lo maravilloso es la más útil a la hora de abordar los textos que popularmente se conocen como "fantasía", pues en estos por lo general es necesario admitir otro tipo de leyes físicas y epistemológicas que sostengan el mundo narrado, ya que las del mundo que conocemos no bastan para explicarlo. Se trata pues de fenómenos sobrenaturales que se confirman como tales.

\section{Tolkien: choque de mundos}

En su ensayo "Sobre los cuentos de hadas", J.R.R. Tolkien (2002) propone una visión particular de lo que él llama "cuento de hadas":

...los cuentos de hadas no son en el uso diario de la lengua relatos sobre hadas o elfos, sino relatos sobre el País de las Hadas, es decir, sobre Fantasía, la región o el reino en el que las hadas tienen su existencia. Fantasía cuenta con muchas más cosas que elfos y hadas, con más incluso que enanos, brujas, gnomos, gigantes o dragones: cuenta con mares, con el sol, la luna y el cielo; con la tierra y todo cuanto ella contiene: árboles y pájaros, agua y piedra, vino y pan, y nosotros mismos, los hombres mortales, cuando quedamos hechizados (p. 19).

\section{(a) $\mathbb{Q} \Theta($}

La Revista Estudios es editada por la Universidad de Costa Rica y se distribuye bajo una Licencia Creative Commons Atribución-NoComercial-CompartirIgual 3.0 Costa Rica. Para más información envíe un mensaje a 
Especial: Humanismo e investigación: una actividad permanente en la Escuela de Estudios Generales

Así, para Tolkien el "cuento de hadas" es aquel que involucra ese cruce entre lo sobrenatural y lo natural, pues además de la selección de fauna y entidades sobrenaturales que proporciona, menciona también los astros, el mundo y a los seres humanos que lo habitan.

Lo fundamental es la aparición de lo que Tolkien Ilama "Magia":

...cuento de hadas es aquel que alude o hace uso de Fantasía, cualquiera que sea su finalidad primera: la sátira, la aventura, la enseñanza moral, la ilusión. La misma Fantasía puede tal vez traducirse, con mucho tino, por Magia, pero es una magia de talante y poder peculiares, en el polo opuesto a los vulgares recursos del mago laborioso y técnico (p. 21).

Término que, posteriormente, substituye por "encantamiento":

El Encantamiento genera un Mundo Secundario accesible tanto al creador como al espectador, para mayor gozo de sus sentidos mientras se hallan inmersos en él; y en estado puro es artístico tanto en deseos como en designios. La Magia produce, en cambio, o pretende producir, una alteración en el Mundo Primario. No importa a quién se atribuya su práctica, hadas o mortales, aparece distinta de las otras dos manifestaciones; no es un arte, sino una técnica; desea el poder en este mundo, el dominio de las cosas y las voluntades (p. 67).

Es posible encontrar aquí paralelos entre Tolkien y Todorov, pues lo que aquella llama "Magia" se corresponde con lo que este considera "extraño", o un hecho que aparenta ser impropio del mundo real pero termina siendo un truco, una manipulación de lo natural que solo aparenta ser sobrenatural. Por otro lado, el encantamiento produce un Mundo Secundario, lo que se puede tomar como la admisión de nuevas leyes físicas que expliquen el fenómeno. Así, para Tolkien existe un Mundo Primario, el mundo real, en el que se produce un Mundo Secundario, el narrado donde ocurren los prodigios. Esta dualidad de mundos será muy recurrida en el análisis de este trabajo.

\section{(c) (i) (9)}

La Revista Estudios es editada por la Universidad de Costa Rica y se distribuye bajo una Licencia Creative Commons Atribución-NoComercial-CompartirIgual 3.0 Costa Rica. Para más información envíe un mensaje a revistaestudios.eeg@ucr.ac.cr. 
Especial: Humanismo e investigación: una actividad permanente en la Escuela de Estudios Generales

\section{Aurenthal: escritores y magos}

Aurenthal cuenta la historia de Steven y Gabriel, dos jóvenes quienes, ante la petición de Alfredo, abuelo de Gabriel, deben emprender la finalización de una novela que, dadas las condiciones de escritura que utilizó su autor original, Edgar Ardoni, está provocando la desaparición de obras completas de escritores aparentemente al azar. La novela, titulada también "Aurenthal" cuenta una historia llena de magia y prodigios, lo cual convierte el texto en una suerte de gran relato enmarcado. Las particularidades del manejo de lo sobrenatural y prodigioso serán estudiadas en los siguientes apartados.

\section{Resistencia epistemológica: un mundo frente a otro}

Por "resistencia epistemológica" entendemos la reacción de un ser pensante, con una noción de realidad obtenida por su experiencia de vida, ante hechos que desafían radicalmente dicha noción y lo ponen frente a un nuevo mundo con posibilidades, hasta ahora para él, inimaginables.

Los personajes de Aurenthal enfrentan una serie de sucesos extraordinarios que violentan su noción de realidad. Para comprender esta violencia es necesario tener presente el Mundo Secundario descrito. Resulta conveniente para este propósito leer con atención el íncipit de la novela:

Era una tarde de jueves, tranquila y soleada. Los viejos árboles que rodeaban todo el residencial estaban en flor. En el parque, varios niños con unas cuerdas y unos aros de metal jugaban uno de esos divertidos juegos, en los que bastan muy pocas cosas reales, porque todo lo demás lo pone la imaginación. Todo parecía estar en la más completa quietud. Era una tarde común de jueves, tranquila y soleada (Rodríguez, 1991, p. 9).

\section{(C) $(0 \bigcirc$}

La Revista Estudios es editada por la Universidad de Costa Rica y se distribuye bajo una Licencia Creative Commons Atribución-NoComercial-CompartirIgual 3.0 Costa Rica. Para más información envíe un mensaje a 
Especial: Humanismo e investigación: una actividad permanente en la Escuela de Estudios Generales

Este primer párrafo se comporta cíclicamente en tanto su primera y última frases son prácticamente idénticas y hacen referencia al tiempo narrado: la acción transcurre durante una tarde de jueves. En cuanto al espacio, se describe un residencial rodeado de árboles en cuyo parque los niños se divierten. Si bien existe ya una insinuación de hibridez (los juegos de los niños involucran tanto cosas reales como imaginación), la escena es perfectamente factible en el Mundo Primario. De hecho, la reiteración del tiempo y la situación descrita crean una sensación de calma: no hay sobresaltos ni conflictos en esa soleada tarde de jueves. El segundo párrafo presenta finalmente al personaje, manteniendo la misma situación, podría decirse, realista:

Un autobús escolar se detuvo a un costado del parque, frente a un gran condominio. Varios muchachos bajaron, despidiéndose de los demás, para luego correr en múltiples direcciones. Uno de ellos, rubio y delgado, cruzó la calle con prisa, hacia una casa esquinera, grande, de dos pisos, rodeada de un hermoso jardín. Abrió el portoncito metálico con descuido, y entró corriendo, dando un fuerte portazo (pp. 9-10).

Aunque no se dan marcas temporales ni espaciales precisas que permitan ubicar la narración en algún momento o lugar del Mundo Primario, la ambientación basta para afirmar que el Mundo Secundario se le parece lo suficiente como para ser su homólogo. Más aun cuando el niño descrito, que resulta ser Gabriel, uno de los protagonistas, menciona su reciente examen de Historia y, posteriormente, recibe la indicación de que llegó una carta para él, la cual se mojó pues permaneció en el buzón toda la mañana, cuando llovió. Tanto el sistema educativo como los medios de educación y los fenómenos ambientales son propios del Mundo Primario.

El dato más preciso para constatar la relación entre mundos aparece más adelante en la novela, cuando los niños se dirigen a la casa de Alfredo, el abuelo

\section{(ब) $\odot \odot$}

La Revista Estudios es editada por la Universidad de Costa Rica y se distribuye bajo una Licencia Creative Commons Atribución-NoComercial-CompartirIgual 3.0 Costa Rica. Para más información envíe un mensaje a 
Especial: Humanismo e investigación: una actividad permanente en la Escuela de Estudios Generales

de Gabriel. Steven, no muy convencido de haber tomado la decisión correcta con respecto a pasar ahí el fin de semana, reflexiona:

Si no se me hubiera ocurrido llamar a Gabriel, quizá estaría ahora rumbo a la playa con tía Carmen y su familia. O bien, habría podido asistir al juego de fútbol en el Colegio, esta noche. Y ver la transmisión de los premios "Grammy" en la televisión, mañana... (p. 20).

La mención a los premios Grammy es una marca cultural que permite apelar al lector quien, gracias a la mención de ese evento, verá su mundo (el Primario) retratado en el texto, con lo que podrá identificarse más certeramente con el mundo narrado (el Secundario) y los personajes.

Hasta la visita de Gabriel y Steven a la residencia de Alfredo, no existe un solo hecho en la narración que pueda considerarse violento con respecto a la noción de realidad descrita, situación que cambia al narrarse la historia sobre Edgar Ardoni y su proyecto de escritura, el cual, por involucrar el plagio de obras anteriores, provocó que la obra de un escritor desapareciera misteriosamente. Steven y Gabriel reaccionan con resistencia al escuchar la narración de Alfredo, quien de hecho confirma que el escritor fue el primer sorprendido ante los sucesos sobrenaturales que comenzó a experimentar:

Mientras trabajaba en su apartamento, avanzando en la escritura de su narración directamente sobre el manuscrito, Edgar sintió de pronto la sacudida de lo que parecía un fuerte y repentino temblor. Interrumpió la labor y encendió la radio para escuchar alguna información al respecto, pero no hubo nada. Tampoco en la televisión. Eso le pareció raro, pero decidió olvidarlo, y volvió a su trabajo (pp. 46-47, cursivas nuestras).

A partir de este fragmento, los personajes muestran su rechazo o incredulidad con respecto a lo ocurrido con Ardoni. Más aún cuando la historia revela que el temblor solo fue el principio:

\section{(C) $(\Theta \odot$}

La Revista Estudios es editada por la Universidad de Costa Rica y se distribuye bajo una Licencia Creative Commons Atribución-NoComercial-CompartirIgual 3.0 Costa Rica. Para más información envíe un mensaje a 
Especial: Humanismo e investigación: una actividad permanente en la Escuela de Estudios Generales

A la mañana siguiente, nadie comentaba nada sobre el temblor, y Ardoni prosiguió su trabajo normalmente. Había avanzado algunas cuantas páginas más cuando, dos noches más tarde, otro temblor sacudió su apartamento. Salió un momento a la terraza: todo parecía normal. Y al regresar a su mesa, encontró escrito en el cuaderno: “iDetente!: las Cartas Howelianas han desaparecido..." (p. 47).

Ardoni estaba solo, no reconocía la letra de esta enigmática frase y estaba completamente seguro de no haberla escrito. Alguien 0 algo se estaba comunicando con él a través de su manuscrito, hecho que es enfrentado por Ardoni "con el temor propio de quien se enfrenta a lo desconocido" (p. 47), tanto así que incluso considera la posibilidad de estar soñando. Su única posibilidad de aceptar el hecho desde su noción de realidad es atribuirlo a una extraña casualidad, como que "probablemente el cuaderno traía esa frase escrita antes" (p. 48) y él hasta ahora la nota. Tras obviar la situación y continuar con su trabajo durante varios días, una noche, mientras se encuentra de nuevo escribiendo,

un fortísimo temblor hizo estremecerse toda la casa. Los libros y cuadros cayeron al suelo; los muebles se desacomodaron y volcaron... Pero esta vez, justo frente a sus ojos, observó cómo, en un instante, una frase similar a la anterior se dibujaba sola, con trazos firmes y pausados. Un nuevo párrafo, más desconcertante aún, decía: “¡Detente ahora mismo! Has hecho desaparecer a James Howell! ¡Lo has dañado todo! ¡Toda su obra se ha perdido!”. Esta vez no pudo calmar su imaginación con ninguna respuesta lógica. La cabeza le daba vueltas y creyó enloquecer (p. 48).

La reacción de Ardoni no puede ser más clara: se resiste a aceptar los eventos que presencia porque su noción de realidad sencillamente es incapaz de admitirlos. Incluso, la reacción va más allá en esta ocasión pues, en lugar de obviar el suceso y seguir trabajando, Ardoni decide detenerse y dejar su "Aurenthal" inconclusa. Esta vez presencia el momento en que ocurre el hecho sobrenatural, ve con sus propios ojos cómo la frase se dibuja en el cuaderno, por lo que ya no existe manera de negar o explicar: el hecho, si bien imposible,

La Revista Estudios es editada por la Universidad de Costa Rica y se distribuye bajo una Licencia Creative Commons Atribución-NoComercial-CompartirIgual 3.0 Costa Rica. Para más información envíe un mensaje a revistaestudios.eeg@ucr.ac.cr. 
Especial: Humanismo e investigación: una actividad permanente en la Escuela de Estudios Generales

ocurrió. La situación resultante es insoportable para Ardoni, al punto de que decide evitar cualquier acción que pueda provocarla de nuevo y deja de escribir inmediatamente.

Cuando Alfredo concluye su narración, abre un espacio para preguntas. Es natural que los niños las tengan, ya que su noción de realidad tiene que haberse visto violentada con semejante historia. De hecho, las preguntas demuestran dicha violencia: “¿Quién escribió las frases en el manuscrito?”, “¿Y cómo llegaron ahí?” (p. 49). Alfredo, naturalmente, no puede explicar nada. Más adelante agrega una reflexión al mencionar nuevamente a Ardoni:

Edgar detuvo su trabajo indefinidamente, como ya dije antes. Quería convencerse por sí mismo de que todo era un juego de su imaginación, pero era imposible: los signos externos denotaban que era real, aunque inexplicable ( $\mathrm{p}$. 50 , cursivas nuestras).

Según narra Alfredo, Ardoni dedicó mucho tiempo a meditar con respecto a su experiencia, meditación de la que extrajo las siguientes conclusiones:

...primero, James Howel fue escritor y aquellas obras, sus creaciones; segundo, "algo" se había comunicado con él para avisarle que el Howel escritor y toda su obra habían desaparecido; tercero, la causa de la desaparición del autor y su obra fue su propio trabajo: él era el responsable directo de ello; y cuarto, la historia de la literatura había sido variada (p. 50).

Es a partir de este momento que Ardoni, por así decirlo, "cruza el umbral" de lo maravilloso: la resistencia epistemológica ya no es posible, pues sean o no explicables los hechos que se resistió a creer, ahora es comprobable que estos ocurrieron. Aún más: tienen consecuencias de las que él es el único responsable. La noción de realidad de Ardoni ha sido, finalmente, expandida, pues admite la posibilidad de que "algo" se comunique con él a través del manuscrito que ha

\section{(c) (i) (-)}

La Revista Estudios es editada por la Universidad de Costa Rica y se distribuye bajo una Licencia Creative Commons Atribución-NoComercial-CompartirIgual 3.0 Costa Rica. Para más información envíe un mensaje a revistaestudios.eeg@ucr.ac.cr. 
Especial: Humanismo e investigación: una actividad permanente en la Escuela de Estudios Generales

elaborado, así como admite que este trabajo haya provocado una alteración en la historia literaria y, por ende, en la historia humana.

Consideramos importante definir aquí nuestra visión de lo maravilloso. Al leer fantasía del siglo XX, es notable la diferencia con respecto a otros tipos de textos similares. En los cuentos de hadas, por ejemplo, existe una suerte de predisposición a lo sobrenatural, prácticamente es un hecho que contemplaremos fenómenos que desafiarán nuestra noción de realidad. Por ende, cuando estos ocurren, ni personajes ni lector experimentan extrañamiento o alarma. Las maravillas son, pues, parte de esa realidad. Por el contrario, textos contemporáneos (del siglo XX en adelante) suelen presentar los prodigios como desconcertantes, aunque terminen por asumirse como parte de una nueva versión expandida de la realidad.

El rasgo más distintivo de esta corriente es que las historias suelen ambientarse originalmente en lugares y épocas reconocibles del Mundo Primario, para dar paso luego al nuevo mundo de prodigios. Tal es el caso de Peter and Wendy, novela de J.M. Barrie que se ambienta en principio en Londres y luego pasa a la tierra de Nunca Jamás; The Lion, the Witch and the Wardrobe, de C.S. Lewis, incluso se ubica en principio en un momento particular de la historia: Londres durante la Segunda Guerra Mundial, para posteriormente ingresar a la mágica tierra de Narnia. The Wonderful Wizard of Oz, de L.F. Baum, utiliza este recurso también, al ambientarse en principio en Kansas y pasar luego a la titular tierra de Oz. En su prólogo a dicha novela, Baum hace una interesante diferenciación:

...the old-time fairy tale, having served for generations, may now be classed as "historical" in the children's library; for the time has come for a series of newer "wonder tales" in which the stereotyped genie, dwarf and fairy are eliminated, together with all the horrible and bloodcurling incident devised by their authors to point a fearsome moral to each tale. Modern education includes morality;

\section{(c) (i) (2)}

La Revista Estudios es editada por la Universidad de Costa Rica y se distribuye bajo una Licencia Creative Commons Atribución-NoComercial-CompartirIgual 3.0 Costa Rica. Para más información envíe un mensaje a revistaestudios.eeg@ucr.ac.cr. 
Especial: Humanismo e investigación: una actividad permanente en la Escuela de Estudios Generales

therefore the modern child seeks only entertainment in its wonder-tales and gladly dispenses with all disagreeable incident (Baum,1996, p. III).

Baum distingue "cuentos de hadas" de "cuentos de maravillas", apuntando que las moralejas de aquellos ya no son necesarias, por lo que los nuevos cuentos prodigiosos pueden concentrarse en la maravilla y el entretenimiento del lector.

El que dicho prólogo apareciera en 1900 resulta significativo, pues lo expuesto en él es la tendencia de la literatura de fantasía aparecida en el siglo. Esta es la que, a nuestro criterio, recibe el nombre de literatura maravillosa, pues las maravillas solo son tales si alguien las percibe como imposibles y, por ellos, sorprendentes, increíbles. Aunque dicha primera impresión termina por diluirse al aceptar que la realidad es más amplia de lo que se creía, de lo cual son pruebas esos prodigios a los que personajes y lector se enfrentan.

Aurenthal, como se viene apuntando, presenta esa ubicación inicial en un mundo homólogo al Primario, en el que las cosas funcionan con total normalidad y hasta hay marcas culturales que nos hacen sentir en nuestra propia versión de la realidad. Por ello, la irrupción de hechos sobrenaturales impresiona a los personajes, produciendo una reacción de impacto y negación inicial.

Con todo, por lo comentado hasta el momento, Alfredo y los niños no han experimentado de primera mano lo vivido por Ardoni, por lo que su noción de realidad permanece intacta. Hasta el momento la novela no ha hecho más que poner en boca de uno de sus personajes una narración ciertamente increíble, cuya veracidad aún está por confirmarse.

La intención de Alfredo al reunir a Steven y Gabriel y contarles la historia es encargarles la conclusión del trabajo de Ardoni, única salida para el problema que el escritor creó con su proyecto. El grupo procede a ejecutar un plan que

\section{(C) $(0 \otimes$}

La Revista Estudios es editada por la Universidad de Costa Rica y se distribuye bajo una Licencia Creative Commons Atribución-NoComercial-CompartirIgual 3.0 Costa Rica. Para más información envíe un mensaje a 
Especial: Humanismo e investigación: una actividad permanente en la Escuela de Estudios Generales

revertiría la situación, aunque puede entreverse a su vez la intención de comprobar que todo lo relatado sea cierto.

Alfredo está en la misma posición de los niños: solo conoce la historia de oídas, no ha experimentado en carne propia ninguno de los hechos desafiantes y violentos. De momento, solo existe un aspecto que parece inclinarlo a dar crédito a lo que le contó Ardoni: el hecho de que no exista registro alguno de quién fue James Howel ni de su obra, las "Cartas Howelianas". Además, la desaparición del manuscrito en que Ardoni trabajaba lo intriga muchísimo. En busca de algún dato de interés, Alfredo termina conversando con Tomás Bennet, el editor de Ardoni quien, como consigue averiguar, ha intentado reproducir el plan del escritor de elaborar historias mediante plagios de otras. La duda con respecto a si el editor tuvo éxito lleva a Alfredo a ensayar sus propios textos siguiendo el sistema de plagio, mas no consigue el resultado esperado. Al contárselo a los niños, les menciona que la explicación, a su criterio, radica en que "Alguien" está evitando que se den más pérdidas de escritores. Esta entidad sería la misma que escribió los enigmáticos mensajes en el manuscrito de Ardoni. La única manera de burlar la seguridad impuesta por Alguien es "reabrir" el manuscrito, continuar la historia original ahí donde quedó. Ardoni la dejó inconclusa justo cuando realizaba uno de los plagios y Alfredo conoce exactamente la cita que lo constituía. Gracias a este hecho, los niños consiguen continuar "Aurenthal”, siempre con el procedimiento de plagiar diversos textos, y provocar la pérdida de nuevos autores. El plan de Alfredo es generar tantas pérdidas como sea posible para expandir el desequilibrio entre el tiempo literario y el humano, concluir "Aurenthal" y luego destruirla para devolver todo a la normalidad.

Ambos jóvenes se muestran escépticos desde un principio; Gabriel muestra su frustración ante la idea de que Howel haya podido desaparecer sin más de la historia de la humanidad con una afirmación contundente: “¡Santo 
Especial: Humanismo e investigación: una actividad permanente en la Escuela de Estudios Generales

Cielo!: eso es como si ahora yo me inventara el nombre de un supuesto autor y toda esa historia, como verdadera..." (p. 51). Steven no puede evitar susurrarle a Alfredo: "Todo lo que nos ha contado hoy, señor Howell, ¿ocurrió de verdad?" (p. 54). Aunque por lo general Steven es el más analítico (o, tal vez, precisamente por eso), su noción de realidad se resiste epistemológicamente ante la violencia a la que está siendo sometida. La resistencia se vuelve más palpable aún gracias a las múltiples ocasiones en que los personajes muestran incredulidad. Refiriéndose a lo que le contó Ardoni, Alfredo señala que “...pensaba que Edgar había perdido su sano juicio" (p. 71), así como que "icosas muy extrañas ocurrieron aquellas noches!" (p. 86); ante el plan que propone Alfredo, Steven señala: "todo son conjeturas, y nada más..." (p. 86); pero sobre todo, el sobresalto es notable cuando comprueban que el procedimiento descrito por Ardoni funciona efectivamente: “¡Dios mío! ¡Es verdad!... ¡Todo es verdad!- Balbuceó Steven, sentándose y llevándose las manos a la cara: estaba muy asustado. — Parece un sueño-Casi sollozó el señor Howell" (p. 125).

A partir de este momento, tanto Alfredo como Steven y Gabriel experimentan la misma expansión de su noción de realidad que sufrió Ardoni en su momento. Ahora que descubrieron que el procedimiento de plagios provoca realmente la desaparición de obras aleatorias, el mundo no puede ser el mismo para ellos. A partir de aquí la tensión no recaerá en la posibilidad de que este efecto material de determinado uso literario sea posible, sino en que sus consecuencias sean nefastas y provoquen pérdidas irreparables. Nadie dudará más de que es posible alterar el mundo gracias a la escritura, sino que todos tendrán que asumir la responsabilidad que viene con esa certeza. El mundo, así sea solo para Alfredo, Steven, Gabriel y Ardoni (también para Bennet, como queda demostrado al final de la novela), ha cambiado. El Mundo Secundario ha evolucionado para convertirse en un mundo diferente, un Mundo Terciario que,

La Revista Estudios es editada por la Universidad de Costa Rica y se distribuye bajo una Licencia Creative Commons Atribución-NoComercial-CompartirIgual 3.0 Costa Rica. Para más información envíe un mensaje a 
Especial: Humanismo e investigación: una actividad permanente en la Escuela de Estudios Generales

aunque es una expansión del anterior, es un mundo en sí mismo pues no está al alcance de cualquiera, solo de aquellos que, de alguna u otra forma, se han visto involucrados en el proyecto originalmente concebido por Ardoni.

Alguien es, sin duda, la muestra más palpable de ese nuevo Mundo Terciario que los personajes han descubierto. Esta enigmática entidad, de la cual no se conoce más que los mensajes que hace llegar a los manuscritos, tiene un efecto determinante en la historia, puesto que no solo trató de detener a Ardoni y frustró los intentos tanto de Alfredo como de Bennet de repetir el proceso, sino que es el responsable de que tanto el filólogo como Steven y Gabriel puedan percibir cuando la obra de un autor desaparece, ayuda sin la cual les hubiera sido imposible comprobar que el proceso de plagio funcionaba y era reversible. Además, cerca del final de la novela se encarga de distraer a Bennet, quien se ha propuesto frustrar el plan de Alfredo para que los niños puedan cerrar la historia adecuadamente. La misma entidad se presenta en ese momento: "los nombres identifican a las cosas conocidas, Steve, pero a mi casi nadie me conoce. Sin embargo, una persona a quien tú quieres mucho cierta vez me denominó ‘Alguien'... Soy Alguien: el guardián del tiempo literario...” (p. 241).

En el mundo planteado finalmente por Aurenthal, el tiempo literario está en un delicado equilibrio con el tiempo humano, equilibrio que puede verse amenazado por ciertas prácticas particulares de escritura, las cuales podrían resultar en la pérdida de obras completas de diferentes escritores. El tiempo literario tiene un guardián, una entidad desconocida e innombrada que adopta el epíteto de "Alguien" para presentarse ante los personajes. Alguien, por lo que da a conocer el texto, podría asumirse como un ser de puro lenguaje, ya que sus únicas maneras de interacción son los mensajes escritos que deja. Este mundo contrasta fuertemente con el planteado al inicio de la novela, el cual no se diferenciaba en nada del Mundo Primario. La noción de realidad de los personajes,

La Revista Estudios es editada por la Universidad de Costa Rica y se distribuye bajo una Licencia Creative Commons Atribución-NoComercial-CompartirIgual 3.0 Costa Rica. Para más información envíe un mensaje a 
ISSN 1659-3316

Juan Pablo Morales Trigueros

Especial: Humanismo e investigación: una actividad permanente

en la Escuela de Estudios Generales

que no tendría por qué ser diferente de la del lector, se ve violentada ante los hechos narrados, lo cual genera una resistencia epistemológica que va cediendo conforme se confirma que lo ocurrido da cuenta de una realidad desconocida pero factual. Por ende, percibimos un Mundo Terciario que ha venido a sustituir o expandir al Secundario originalmente propuesto. En palabras del propio Alfredo, "la influencia de los libros sobre la Humanidad (...) es mayor de lo que se cree" ( $p$. 58).

Por tanto, consideramos que Aurenthal califica efectivamente como novela maravillosa. Tenemos tanto el Mundo Secundario homologado al Primario como la progresiva irrupción de un Mundo Terciario que viene a violentar la noción de realidad de los personajes (y del lector), quienes se resisten epistemológicamente a tal violencia. Dicha noción es finalmente expandida en favor de la aceptación de un mundo nuevo o, más precisamente en este caso, un mundo más vasto de lo que hasta ahora era conocido, cuyas posibilidades y leyes difieren de las tenidas como reales.

Sin embargo, existen otras implicaciones de su entramado narrativo que vale la pena considerar, no tanto para admitirla o descartarla como maravillosa, sino para reconocer las particularidades del texto que la convierten en algo más.

\section{Relato enmarcado: "Aurenthal" dentro de Aurenthal}

En Aurenthal aparece un relato enmarcado que, de hecho, es el eje alrededor del que gira toda la historia. Se trata del "Aurenthal" de Edgar Ardoni, el escritor venido a menos que generó la grieta en el tiempo por la copia de pasajes textuales de otros textos. Tomándolo aisladamente, el relato presenta un mundo que contiene maravillas ocultas, las cuales que serán tales tanto para el contexto que recibe el texto como para algunos de sus personajes, poco o nada habituados

La Revista Estudios es editada por la Universidad de Costa Rica y se distribuye bajo una Licencia Creative Commons Atribución-NoComercial-CompartirIgual 3.0 Costa Rica. Para más información envíe un mensaje a revistaestudios.eeg@ucr.ac.cr. 
Especial: Humanismo e investigación: una actividad permanente en la Escuela de Estudios Generales

a tales fenómenos. A continuación resumiremos los aspectos que más nos interesan del argumento de ese relato enmarcado para comentarlos.

En la tierra de Aurenthal, la magia fue una vez motivo de un conflicto bélico, pero los años han pasado y esos acontecimientos forman parte de los anales históricos. No obstante, ciertas agitaciones en las ciudades de Ostiantel y Daren, que auguran una nueva guerra, así como el hallazgo de un texto antiguo que parece contradecir la historia conocida, llevan al sabio Barnald, consejero del rey, a sospechar que la magia está renaciendo: casi mil años atrás, los cinco magos más poderosos del Consejo de Lowenthal decidieron concentrar sus poderes en Al-Ranir, el Círculo de Poder, que permitiría a su poseedor dominar el mundo. Los cinco magos restantes, para combatir a Al-Ranir, forjaron la espada Alister, en la cual depositaron todo su poder. La historia cuenta que la Gran Guerra llevó a la destrucción del Círculo, pero el antiguo texto descubierto por Barland habla de la fragmentación del mismo. El sabio reflexiona que las ciudades rebeldes podrían haber reunido los fragmentos del Círculo y piensan usarlo en su rebelión contra Agentel, capital de Aurenthal. De ser así, la única salida es recuperar la espada, librarla del embrujo en que cayó al fragmentar a Al-Ranir, y usarla para, esta vez, destruirlo para siempre. Ante la situación,

Barnald aseguró, entonces, que aún había alguna esperanza: él tenía noticias de que la Magia no había desaparecido del todo en Aurenthal, porque en algún lugar de la Cordillera de Iranthalen vivía aún un aprendiz de mago, un hechicero llamado Nalinor, el único que sobrevivió a la Gran Guerra. El Consejo le había encomendado una misión secreta, enviándole lejos, sólo con el propósito de que no estuviera presente en la desaparición de los Magos ni en la batalla final. Quizás él poseería el poder suficiente para romper el embrujo de la espada. Era la única salida que tenían, porque los Magos se habían extinguido ya (Rodríguez, 1991, p. 107).

Es así como el príncipe Rijart se ofrece voluntariamente para buscar al último mago y, con su ayuda, tratar de recuperar la espada. El príncipe es el 
Especial: Humanismo e investigación: una actividad permanente en la Escuela de Estudios Generales

cuarto hijo de una familia de seis, joven, nativo de un mundo donde la magia está relegada a los libros de historia. Como dice Howell al terminar su narración, "partió hacia lo desconocido" (p. 107).

Considerando "Aurenthal" como un texto aparte inserto en Aurenthal, la similitud con el cuento de hadas es clara, puesto que las maravillas son recibidas como parte del mundo real al fin y al cabo. Sin embargo, existen diferencias. Las más claras son que el cuento de hadas está escrito con la particular intención de dar una enseñanza, sus personajes suelen ser arquetipos y los hechos maravillosos se narran con toda naturalidad, buscando más bien neutralizarlos. Comparten con el mito y el texto religioso el hecho de que ocurren en tiempos y espacios tan remotos que las maravillas se atribuyen a posibilidades que el Mundo Primario alguna vez pudo albergar. Los textos maravillosos, por su parte, se ambientan en lugares definidos pero ficticios (Narnia, la Tierra Media, Fantasía, Oz, Nunca Jamás, Aurenthal) que suelen tener sus propios calendarios, con períodos y épocas definidos. Así, las maravillas narradas, aunque en ciertos casos son parte del Mundo Secundario, están supuestas a conmover al lector, violentando su noción de realidad, aunque finalmente se apele a la suspensión de su incredulidad. En este caso, Rijart está aislado tanto temporal como espacialmente de la magia, por lo que su noción de realidad coincide con la del lector. No obstante, al salir al mundo entra en contacto con la magia, lo que produce el efecto maravilloso. Es el mismo caso de los hobbits en El Señor de los Anillos, quienes en la comarca viven una vida exenta de peligros o magia y se ven frente a estos al salir al mundo, con lo que sufren una expansión de su noción de realidad.

Cabe resaltar que la historia de Ardoni llega precisamente hasta esa frase sobre "lo desconocido". Es a partir de entonces que Steven y Gabriel deben partir a su vez hacia lo desconocido al emprender la redacción del texto. El mismo

La Revista Estudios es editada por la Universidad de Costa Rica y se distribuye bajo una Licencia Creative Commons Atribución-NoComercial-CompartirIgual 3.0 Costa Rica. Para más información envíe un mensaje a 
Especial: Humanismo e investigación: una actividad permanente en la Escuela de Estudios Generales

Gabriel lo nota: “¿no encuentras alguna analogía, algún paralelismo, entre la misión de Rijart y la nuestra, ambas a punto de comenzar?" (p. 110) le pregunta a su amigo. También el narrador enfatiza el hecho: "En ese momento, para un príncipe de papel y dos estudiantes de secundaria, había comenzado verdaderamente la aventura" (p. 112). Los personajes de ambos niveles narrativos comparten su situación, todos ante la súbita expansión de su mundo.

El relato enmarcado es una estrategia utilizada de más de un modo en Aurenthal. "Aurenthal", la de Ardoni, es presentada en primer lugar a través de la voz de un personaje, cuando Alfredo la enuncia para sus invitados y, de paso, para el lector. El manuscrito está extraviado, por lo que la única fuente para conocer la historia es la memoria de Alfredo, la cual puede haber modificado la narración. De hecho, salvo una ocasión al principio (indicada por el propio Alfredo), es imposible percibir los fragmentos de otros libros que Ardoni utilizó al escribir. El estilo y las palabras con que la historia se fraguó originalmente son irrecuperables.

En el capítulo VIII los niños comienzan a redactar la continuación de la historia. Es a partir de entonces que la novela presenta directamente el texto de "Aurenthal", pero que ya no es de Ardoni, sino de Steven y Gabriel. Este se lee directamente al ser escrito por los niños, pero hay que tener presente que la narración tiene su propio narrador omnisciente. Así, se lee un relato enunciado por un narrador omnisciente que es a su vez enunciado por dos personajes que son a su vez enunciados por el narrador omnisciente general de la novela. Esa superposición de narradores termina de configurar un proceso que se viene anunciando desde el relato de Alfredo: la novela contiene a la novela, es un libro dentro de otro libro. "Aurenthal" está dentro de Aurenthal y una no puede ser sin la otra, puesto que el contenedor narra la historia de su contenido, el cual es su razón de ser. La homología de los títulos no es inocente: Aurenthal se llama igual

La Revista Estudios es editada por la Universidad de Costa Rica y se distribuye bajo una Licencia Creative Commons Atribución-NoComercial-CompartirIgual 3.0 Costa Rica. Para más información envíe un mensaje a 
ISSN 1659-3316

Juan Pablo Morales Trigueros

Especial: Humanismo e investigación: una actividad permanente

en la Escuela de Estudios Generales

que "Aurenthal" porque son prácticamente lo mismo, manteniendo su independencia aun así.

La relación entre las situaciones de Rijart y de Steven y Gabriel es un reflejo de este intercambio de planos narrativos. Rijart y los niños que escriben su aventura se encuentran en situaciones similares, lo que refuerza la relación entre las realidades. Por esta razón, sería inadecuado afirmar que el mundo de Alfredo, Steven y Gabriel es el Secundario y el de Rijart el Terciario, pues entre estos mundos no hay un intercambio propiamente dicho, los personajes no cruzan de un mundo a otro como en Mundo de Tinta o La Historia Interminable, textos en los que el mundo del libro es tan consistente y vasto como el real. En cada relato, en el marco y el enmarcado, puede notarse un mundo y su contraparte. Aunque es claro que en el de Rijart las maravillas no se presentan de manera tan violenta, estas desestabilizan al joven, quien "no perdió la ecuanimidad, aunque estaba sumamente nervioso" (p. 119) al enfrentarse a un misterioso árbol parlante, la primera manifestación de la magia antigua de Aurenthal que encuentra en su camino. El hecho es pronto aceptado y sobrellevado por Rijart (aunque él probablemente nunca ha presenciado la magia, está informado de ella por la propia naturaleza de su misión), pero en un principio siente un sobrecogimiento que genera el efecto maravilloso.

Steven, Gabriel y los demás personajes también se ven ante hechos inexplicables, pero los terminan aceptando en una expansión completa de su noción de realidad. Los temblores y los mensajes que vio Ardoni en el manuscrito eran solo una pequeña muestra de lo que estaba por venir, lo cual se evidencia en el capítulo XV, titulado "Alguien", cuando la entidad homónima se presenta a través del manuscrito de los niños como "el guardián del tiempo literario" (p. 241). Esta entidad es la que ha permitido que los niños y Alfredo recuerden los autores que han desaparecido, así como la que ha bloqueado el manuscrito que posee

La Revista Estudios es editada por la Universidad de Costa Rica y se distribuye bajo una Licencia Creative Commons Atribución-NoComercial-CompartirIgual 3.0 Costa Rica. Para más información envíe un mensaje a revistaestudios.eeg@ucr.ac.cr. 
Especial: Humanismo e investigación: una actividad permanente en la Escuela de Estudios Generales

Bennet para impedir que se entere de lo que ocurre. Esta misteriosa entidad pertenece a una realidad más allá de la de los otros personajes. De hecho, nunca se le percibe o describe sino a través de sus mensajes escritos. Es, por tanto, un ente lingüístico que apoya la causa de Alfredo y los niños. Incluso se desdobla como lector y escritor, pues afirma "he seguido muy de cerca vuestro trabajo" (p. 242) y más adelante, "yo entretendré a Bennet, haciéndome pasar por vosotros en el manuscrito original" (p. 243). Alguien ha leído el trabajo de los niños y puede también discutir por escrito con Bennet, algo que ya había hecho con Ardoni. La literatura es pues una realidad en sí misma en el mundo de Aurenthal porque, además de que su práctica afecta al mundo real de los personajes, existe un ente encargado de velar por el adecuado equilibrio entre la realidad literaria y la extra literaria. Los seres humanos, con su actividad, son capaces de alterar ambas realidades, así como este ser lingüístico es capaz de alterarlas a su vez. Ese es, finalmente, el cruce maravilloso de realidades que presenta la novela.

6. Lo meta maravilloso: revisionismo y auto referencialidad.

Tras considerar las implicaciones del relato enmarcado, el caso de Aurenthal como novela maravillosa resulta particular, ya que el mundo violentado no es precisamente un mundo paralelo, ni siquiera se trata de un espacio topográfico u ontológico propiamente dicho, sino de un uso particular de una disciplina artística (la literatura) que genera efectos singulares y violentos, expandiendo los límites de la realidad narrada. En el mundo de Alfredo Howell, Steven y Gabriel, un experimento literario tiene consecuencias tangibles, las cuales solo unos cuantos son capaces de descubrir. Mientras para el resto de la población la realidad permanece intacta, para los implicados esta no será nunca la misma, pues han descubierto que ciertos manejos del material literario la afectan

\section{(c) (i) (-)}

La Revista Estudios es editada por la Universidad de Costa Rica y se distribuye bajo una Licencia Creative Commons Atribución-NoComercial-CompartirIgual 3.0 Costa Rica. Para más información envíe un mensaje a revistaestudios.eeg@ucr.ac.cr. 
Especial: Humanismo e investigación: una actividad permanente en la Escuela de Estudios Generales

drásticamente. Ingresan pues a un mundo otro que permanece latente en el mundo cotidiano, un mundo literario y/o lingüístico.

El hecho de que sea la literatura el instrumento capaz de transformar la realidad genera un sentido especial. Durante su relato, Alfredo señala que Ardoni se vio ante algo que "no comprendía en absoluto, tal como nos sucede ahora a nosotros" (p. 47). Esa frase da cuenta de los múltiples planos narrativos de la obra: el narrador omnisciente cuenta la historia de Alfredo Howell, quien a su vez cuenta la historia de Edgar Ardoni. El "nosotros" de Howell en la frase los envuelve no solo a él y a sus invitados, sino también al lector, que no recibirá los eventos descritos sin que su noción de realidad sea violentada. Se trata de una especie de recursividad textual: el texto crea niveles narrativos contenidos unos dentro de otros, en el centro de los cuales el lector es apelado. Al ser el tema central la literatura misma, la novela se convierte en una meta-novela, novela sobre novelas, literatura sobre los efectos de la literatura en la realidad.

\section{Balance final: una variante de lo maravilloso}

Concluimos que Aurenthal es una novela meta maravillosa, pues el efecto maravilloso se da en ella pero de una manera particular. Más allá del cruce de dos mundos, Aurenthal plantea la maravilla desde la creación, la expansión de la realidad a partir de la labor literaria humana, que abre los horizontes de lo real y permite la aparición de fuerzas desconocidas más allá de lo hasta entonces considerado real.

Resulta particularmente interesante el hecho de que la novela incluya una reflexión con respecto a la "literatura fantástica". Steven afirma que le gusta este tipo de literatura, a pesar de que haya quienes afirman que es para niños. Alfredo se apura a refutar esta noción, señalando que esta categoría literaria es capaz de

La Revista Estudios es editada por la Universidad de Costa Rica y se distribuye bajo una Licencia Creative Commons Atribución-NoComercial-CompartirIgual 3.0 Costa Rica. Para más información envíe un mensaje a revistaestudios.eeg@ucr.ac.cr. 
ISSN 1659-3316

Juan Pablo Morales Trigueros

Especial: Humanismo e investigación: una actividad permanente en la Escuela de Estudios Generales

decir mucho. La afirmación no deja de ser irónica considerando que aparece en una novela cuya contraportada la recomienda para lectores de "12 años en adelante". El protagonismo de personajes infantiles suele relacionarse con la literatura maravillosa, característica que Aurenthal, de hecho, presenta. Además, el consumo de este tipo de textos se relaciona asimismo con la población menor, en lo que se percibe un prejuicio cultural relacionado con la capacidad de suspender la incredulidad que tienen los niños y las niñas. La noción de realidad, podría interpretarse, no está totalmente definida en la infancia, por lo que es más factible que un individuo en esa etapa admita portentos que en otro momento la desafiarían. Esta relación es cuestionable desde muchas posiciones, como la que toma Aurenthal al apuntar que la literatura fantástica es capaz de ser mucho más que narrativa destinada a niños. También puede discutirse la idea de que los adultos sean menos capaces de suspender su incredulidad. De una u otra forma, la relación entre la narrativa fantástica o maravillosa con la infancia resulta arbitraria y cuestionable, hecho que solo señalamos por salirse de los parámetros de este trabajo.

La auto referencialidad juega un papel importante en la estructuración del texto, pues este se configura como una narración que se toma a sí misma como tema, muestra el proceso de escritura y reflexiona sobre sus consecuencias. Con este proceso, genera una serie de planos narrativos que se superponen unos a otros y motivan una suerte de simbiosis en la que un plano necesita del otro para existir. La historia de Ardoni, "Aurenthal", existe ya que es parte de Aurenthal, la de Rodríguez, mientras que esta última tiene como eje aquella, es la historia de una historia y sus consecuencias. Otros textos, como La Historia Interminable y Mundo de Tinta, proponen historias similares en las que la literatura es un tema central. Estas podrían considerarse candidatas a compartir la clasificación meta

\section{(a) $\mathbb{Q} \Theta($}

La Revista Estudios es editada por la Universidad de Costa Rica y se distribuye bajo una Licencia Creative Commons Atribución-NoComercial-CompartirIgual 3.0 Costa Rica. Para más información envíe un mensaje a revistaestudios.eeg@ucr.ac.cr. 
Especial: Humanismo e investigación: una actividad permanente

en la Escuela de Estudios Generales

maravillosa de Aurenthal, aunque dejamos el tema abierto puesto que también desborda las intenciones de este trabajo.

\section{Bibliografía}

Baum, Lyman Frank (1996). The Wonderful Wizard of OZ. New York: Dover Publications..

Rodríguez, L. R. (1991). Aurenthal. San José: Farben.

Todorov, T. (1972). Introducción a la literatura fantástica. Buenos Aires: Tiempo Contemporáneo.

Tolkien, J. (2002). Sobre los cuentos de hadas. En J. Tolkien, Árbol y hoja (págs. 11-100). Barcelona: Minotauro. 